\title{
TOWARDS A BETTER ECOLOGY OF URBAN MOBILITY: THE CASE OF THE CITY OF CONSTANTINE, ALGERIA
}

\author{
KELILBA MOUNIRA \& CHAIB RACHID \\ Mentouri University, Algeria
}

\begin{abstract}
With the expansion of the city of Constantine in Algeria, a major problem is the issue of daily mobility and its coverage by transportation networks. Many inhabitants of the suburbs, for whom commuting is required, make long and costly daily journeys to work or to run errands. In this paper, we focus on the improvement and modernisation of urban transportation in this city. This work aims to facilitate and qualify people's urban mobility by helping them travel under the best possible conditions from point A or "origin", to point B or "destination". This study is intended primarily for urban transport users in Constantine. The technique we envisioned was a questionnaire carried out via the Google Forms service, processed using data processing software and analysed according to prioritisation series. To represent this data and facilitate reading and analysis, we used tables and cross-tabulations. This allowed us to have a clear picture of the problems raised by users. Thus, it is possible to propose the right ideas in terms of the optimal tasks for the operators and the right travel conditions for the users, or even to find common relationships between the organisations and their environment.
\end{abstract}

Keywords: Constantine, commuting, urban transport, urban mobility, Google Forms, Pareto analysis, Pareto staircase, priority actions.

\section{INTRODUCTION}

For years, the problem of urban transportation has been a daily challenge in the city of Constantine, Algeria, in particular for the new centres that have benefited from housing and relocation programmes. The peripheral areas of this city are experiencing a strong population growth, never imagined since independence. In addition, there is an increased need for worker mobility and increased travel to the city of Constantine. This has led to an especially important mobility dynamic towards the centre, resulting from an increased need for worker mobility and a huge increase in travel to Constantine, which has generated a multitude of urban transport problems. In addition, with uncontrolled urban growth of a city initially built for 300,000 inhabitants and whose number has now almost tripled, traffic within the urban fabric is one of the most serious constraints, ever under the simultaneous pressure of both the equipment and transportation crises, which engenders annoyance at its highest point [1]. The issue of daily mobility and its management by the transport systems is a major problem for this city; therefore, reducing the intensity of the commuting problems in this city will be a far from simple matter [2].

The transportation network is the backbone of Constantine, linking its essential elements to its composition [3]-[5]. There is pride in its efficiency and breadth, and the reflection of its soul is perceived by the diversity exhibited [6]-[8]. Henceforth, the decision-makers will be further integrating transport into the heart of city planning and development [9]-[11]. Moreover, it is not enough to talk only about the efficiency of daily travel and transportation; but also about its contribution to the social, economic and cultural health of Constantine's inhabitants [12]-[14].

Until 1987, the State exercised a monopoly on urban passenger transport services, through public undertakings, generally under the responsibility of local authorities [15]. It is in this climate of economic crisis in which public authorities are losing the capacity to finance and develop public transport, and in the face of the financial deficiency of public enterprises, that 
the lifting of the State's monopoly on transport activity took place in 1988, when the community and its member states opened to private investment. However, this poorly controlled growth led to the emergence of serious dysfunctions in the transportation network, notably [16]:

- Poor distribution of resources, relative to demand per transport line.

- Expensive services (fares, subject to frequent increases, are high and not controlled by the State).Weak quality of service, because of a filling rule: The bus does not leave the station until filled up,; thus, contributing to both saturation and anarchic operation of the stations.

- The evolution of the facilities of the transport stations did not follow the same rhythm of increase of the assigned surrounding park, resulting in the deterioration of traffic conditions.

Through this work, we try to highlight the urban transport problems in Constantine, obtained from the analysis of a survey conducted on the various users of urban transportation in this city. We then try to reflect on the approaches processed and mentioned, according to the requests and needs of users, in order to choose current modes of action. A good urban transport network is now more than essential for the proper functioning of any self-respecting city.

\section{METHODOLOGY}

This article describes the progress of an approach we used to improve the problem of urban transportation management practices in the city of Constantine. We base this approach on the participation of all the actors [17], and specifically, the users who are directly involved in the problem (Annex 1). Any approach to assessing the problems experienced in a situation is doomed to failure, without the participation of all actors [18], [19]. This approach must become a source of progress and uninterrupted improvement, to face concrete realities. The quality of this analysis rests on the information, which will be collected on the ground. Our envisaged approach is to use a questionnaire distributed to the different users of urban transport in the city of Constantine, in every way possible. Use of the questionnaire as a quantifiable data collection technique presents a series of questions that are put down in a very definite order. The questions are very simple and legible, in order to gain precise and unambiguous answers (Annex 1).

There are three types of survey questions:

- Single-choice, closed-ended questions where the interviewee only has one answer, such as yes/no questions or screening questions (experience, status, gender, etc.).

- Multiple-choice, closed-ended questions, where the interviewee must select one answer from those proposed.

- Open-ended questions that allow for free answers, which can be helpful and rewarding.

The information obtained was analysed through construction of tables and graphs. The questions were well studied, to allow us to assess the state of urban transport in Constantine, as well as the hierarchisation and prioritisation of the different problems to be faced, according to the characteristics and nature of the users. However, it should be noted that the questionnaire release period and data collection took place at a time of confinement due to the Covid-19 pandemic. This led us to choose the use of Facebook, since the latter is the most used social network in Algeria [20], [21]. We conducted the questionnaire via the Google Forms service, which is a complete form of tool that is free of charge [22]. This allowed us 
to collect a large number (383) of testimonies and opinions. Then, to represent this data and facilitate reading and analysis, we used tables and cross-tabulations. This allowed us to obtain a clear picture of the problems raised by users. Thus, it became possible to propose the right ideas, in terms of the optimal tasks for the operators and the right travel conditions for the users, or even to find reciprocal relationships between the organisations present and their environment.

\section{DATA PRESENTATION AND ANALYSIS}

For a better data analysis, we constructed dynamic cross-tabulations, to create graphs that make it easier for us to read and interpret them. The first step was to highlight all the problems of urban transport in Constantine, cited according to different categories of users. We present this categorisation in Fig. 1.

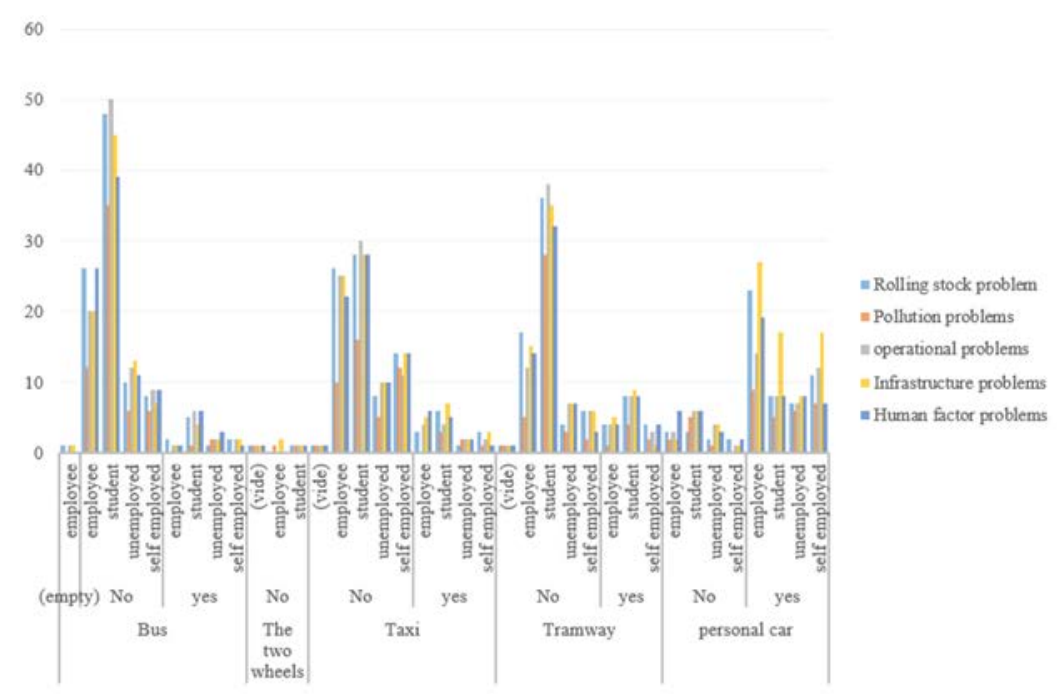

Figure 1: The various problems mentioned regarding urban transport in Constantine.

From the first observation of this graph, we note that people without a personal car and with low revenue, such as students and employees, cite the most problems. This means that most of the problems relate to the use of public transportation to move them so they can carry out their daily activities. In order to identify a pre-prioritisation of the issues raised, we used the Pareto analysis (Fig. 2).

The analysis of this graph shows that the citizens who mark $80 \%$ of the problems are those who do not have a personal car and whom, respectively, take the BUS in first place, the TAXI in second place and the TRAMWAY in third place as chosen methods for their movements. Therefore, to meet our expectations, we must focus our attention on these three categories of problems, to satisfy the most affected citizens, without neglecting the other categories.

Thus, to have a better and effective visualisation in each category of problem (BUS, TAXI and TRAMWAY), it was necessary to define another phase of prioritisation for an efficient order of treatment of these problems; for this, we used an approach inspired by the Pareto staircase mechanism, which meets these requirements. This approach required further application of Pareto's analysis of the issues raised in each category (Fig. 3). 


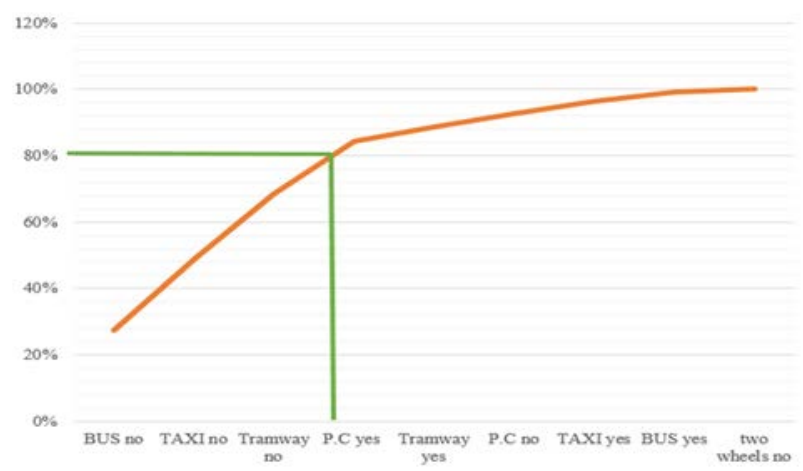

Figure 2: Presentation of pre-prioritisation of problems when treated by the Pareto analysis. (P.C. $=$ personal car.)
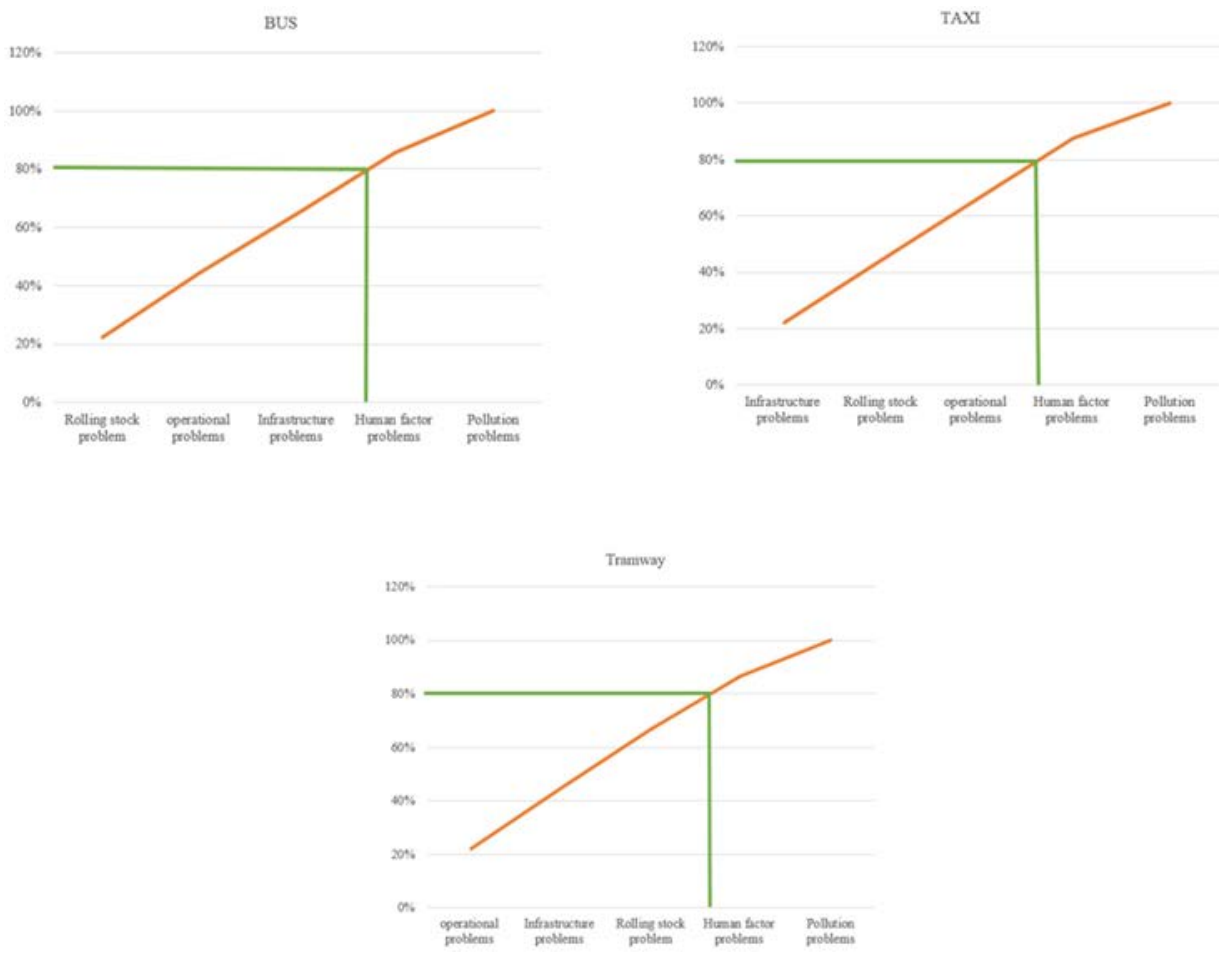

Figure 3: Pareto analysis of questionnaire data applied to the categories of most-mentioned problems. (a) Bus use; (b): Taxi use; and (c) Train/tramway use.

To develop an effective plan of action and climb the steps of efficiency in addressing problem-solving prioritisation [23], we used the Pareto escalator principle in each problem category, to prioritize the actions that most need to be taken. The principle is simple: Lighten the bottom of each step, to allow it to rise. This iterative process consists of alleviating actions 
regarding the problems of a category, where actions on least-mentioned problems are ignored and actions on rarely mentioned ones are deleted, in order to move to the next category. This analysis allowed us to identify the different obstacles influencing each category of problem and find the priorities to engage in each tranche or section.

Following the Pareto precedent classification, the problems of rolling stock, operations and infrastructure were the problems which appear as most prevalently mentioned by users of the BUS, TRAMWAY and/or TAXI. As shown in the diagram in Fig. 4, problems are classified according to the criteria of the Pareto staircase; that is, it shows where we must focus the efforts and priorities of our action, to solve problems without neglecting the problems of pollution and human factors.
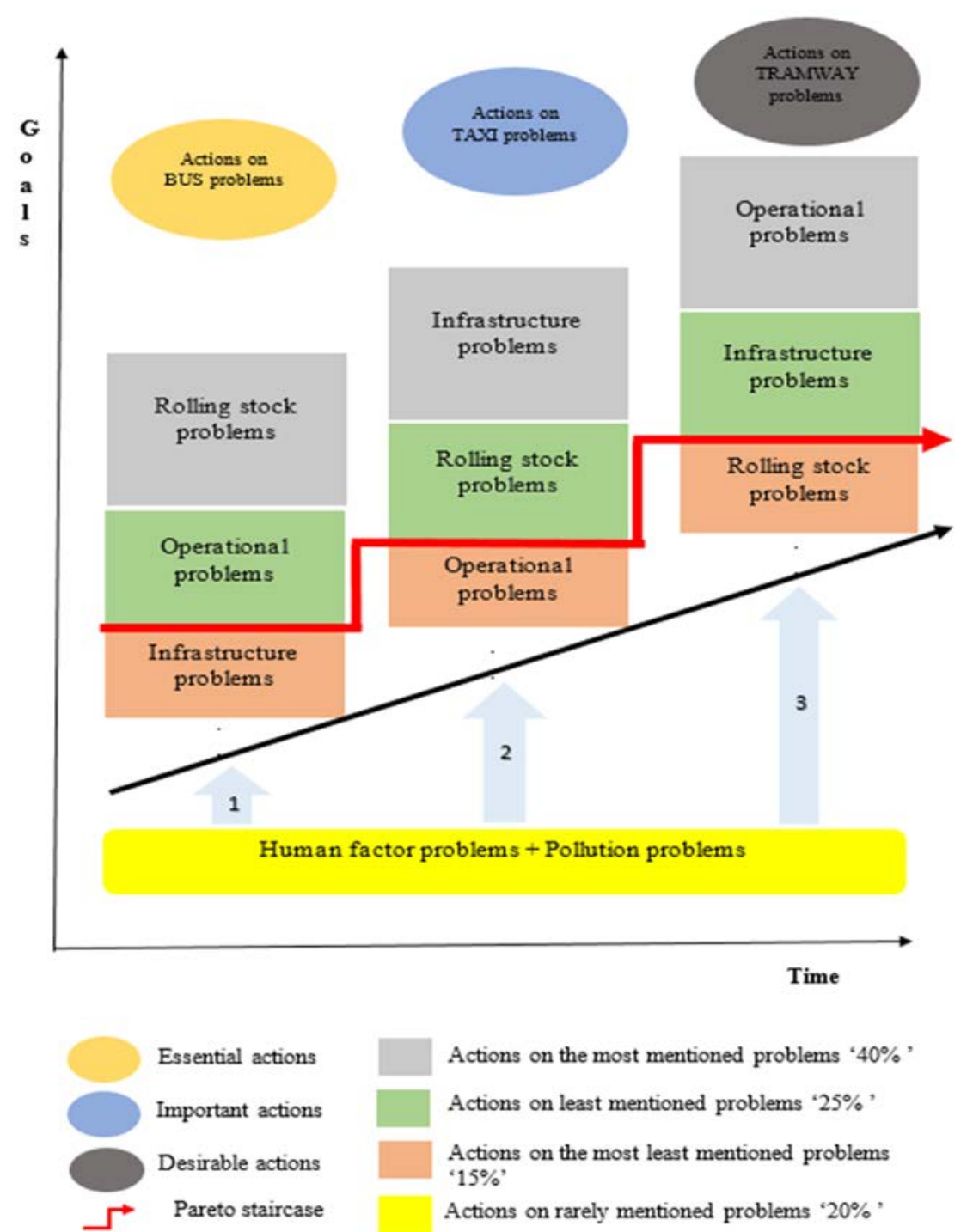

Actions on the most mentioned problems ' $40 \%$ ',

Actions on least mentioned problems ' $25 \%$ '

Actions on the most least mentioned problems ' $15 \%$ '

Actions on rarely mentioned problems ' $20 \%$ '

Figure 4: Application of the Pareto staircase approach to the problems raised. 


\section{DISCUSSION AND RECOMMENDATIONS}

Following these results, we find that the problems raised are mainly marked by low-income citizens and students who do not have a personalized car and who take the BUS in the first place, the TAXI in second and the TRAMWAY third, respectively, for their trips. Therefore, in order to resolve these problems and engage in a continuous improvement process, we propose a set of tasks be assigned in the order specified by the previous approach, or even by priority of action. This solves many predominant problems caused in urban transport and fulfils the needs of this system for better urban ecological mobility.

\subsection{Essential actions on BUS-related problems}

Our analysis shows that the predominant problems related to buses are the problems of rolling stock and operation.

For rolling stock problems: Fig. 5 shows that $75 \%$ of bus users denounce the state of the latter and describe these rolling stock problems as bad, and only $1 \%$ find that the state of the bus is fine, so the buses rolling stock does not satisfy users. These stock problems had a huge influence on well-being and comfort, and even on performance and quality of their work.

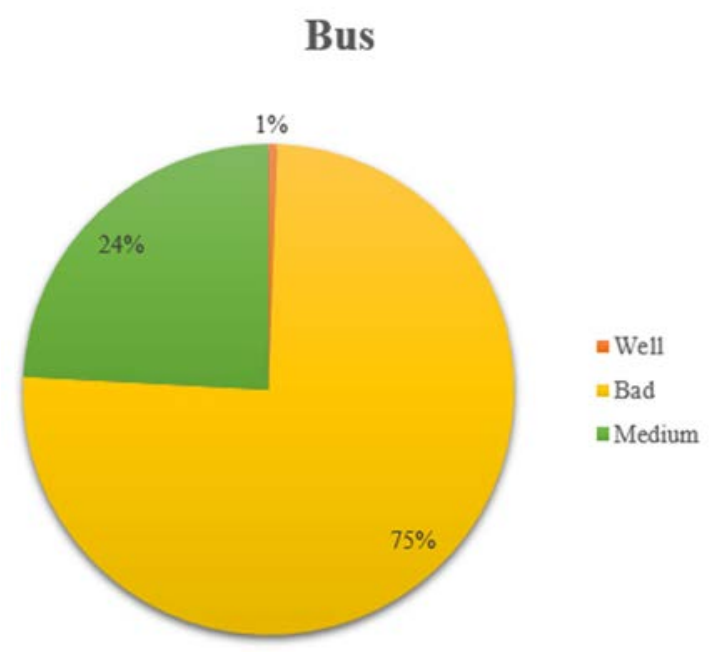

Figure 5: The state of the buses.

For operational problems: According to our Fig. 6 results, the problems mentioned in the questionnaire relate to the planning of bus rotations; $64 \%$ of users find that bus rotations do not help their daily mobility. Users spend a long time in stations, waiting for the arrival of buses, as the rotations are carried out in a disparate manner that is at times not conducive to addressing need. For users, a lot of time is wasted in the stations, and this has a huge influence on the users' daily profitability; however, $60 \%$ of users were satisfied with the bus fares. This was a very positive point for the operation.

To further this evaluation, we proposed the following, for this component: Bus routes having under 10 buses must be withdrawn from traffic, regrouping bus owners into small firms of 10 or more buses and requiring them to respect the corresponding rotation hours, as 


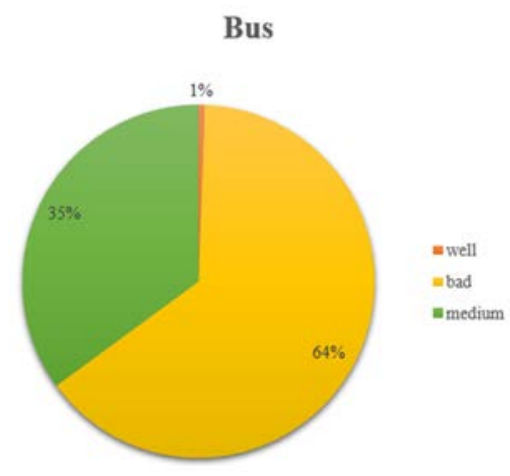

(a)

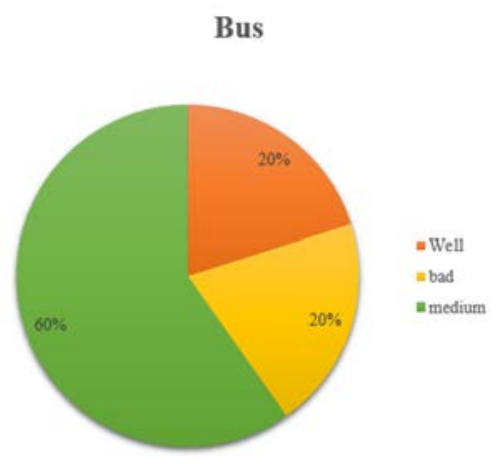

(b)

Figure 6: Operating problems mentioned by BUS users. (a) Planning of bus rotations; and (b) Bus fares.

needed by users (rush hour, weekday, weekend, etc.), or even increase them to increase efficiency in rotation. Facilitate bank loans to renew the bus fleet. Match the bus rotation with the tram rotation and the drop-off points. Impose uniform and service-compatible attire, to increase visual comfort and mutual respect.

\subsection{Important actions on TAXI-related problems}

Analysis shows that predominant problems related to TAXI use are about infrastructure and rolling stock.

\subsubsection{Infrastructure problems}

According to Fig. 7, 42\% of TAXI users find that pavement degradation is the most pronounced problem in terms of infrastructure, compared to $35 \%$ who call for solutions to a lack of parking spaces. This clearly shows that the quality of the infrastructure offered to the user is unpleasant and these issues need to be addressed for better TAXI-related mobility. Here, we have asked that the local authority be up to date in maintaining the pavement after work is done or attend better to its degradation.

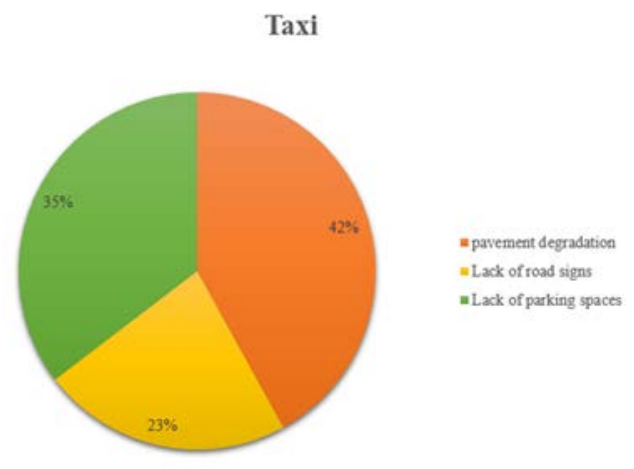

Figure 7: Infrastructure problems mentioned by TAXI users. 


\subsubsection{For operating problems}

Fig. 8 shows that $54 \%$ of users find that comfort in taxis is medium. More than $50 \%$ of users declaim comfort, which proves that about one half of the TAXI fleet is old. Also, $58 \%$ of users think that taxi prices are bad, compared to the service offered. These prices are seen as incompatible with the service performed, which does not meet user expectations. Here, we suggest new cars, with more comfortable lounges designed for users, after five years of driving service.

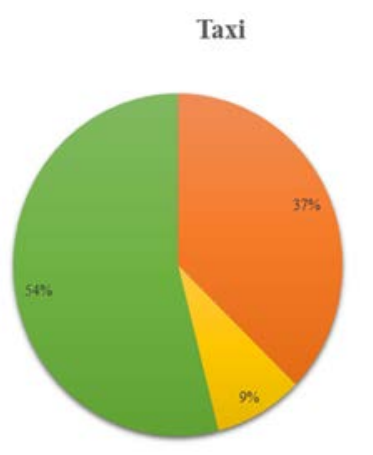

(a)

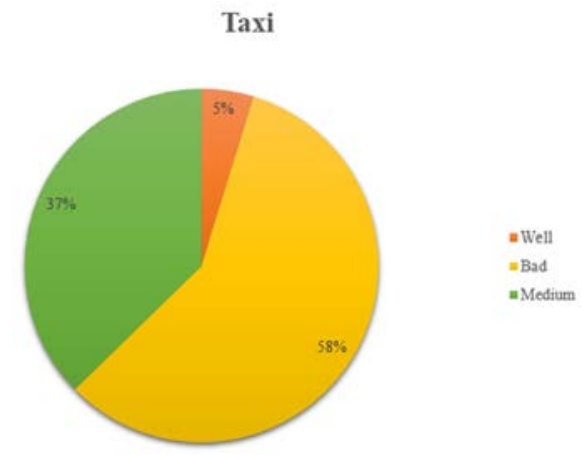

(b)

Figure 8: Operational problems mentioned by TAXI users. (a) The level of comfort in taxis; and (b) Taxi fares.

Following this evaluation, we proposed for this component: We asked the local authority, through the experts, to review the pavement conditions for receiving a pavement coating; to withdraw the authorization of circulation for taxis, once judged by experts, not as currently under the comfort levels imposed by the legislation in force; the application of an efficient parking policy; facilitation of bank loans for the acquisition of new cars; and imposition of uniform and service-compatible attire, to increase visual comfort and mutual respect.

\subsection{Desirable actions on Tramway-related problems}

Our analysis shows that the predominant problems associated with streetcars are operating and infrastructure problems.

\subsubsection{For operational issues}

Fig. 9 shows that $53 \%$ of users are satisfied with the turnaround and tram rates. In our view, this shows that the problem lies in the lack of coordination of the TRAMWAY with other modes of transport and feeder fleets.

\subsubsection{For infrastructure issues}

Fig. 10 shows that $57 \%$ of TRAMWAY users are satisfied with tram stops. We believe that the problems identified in this category by users relate to coordination with other modes of transportation. The lack of coordination between the different modes is denounced by users and solutions demanded, for this category. 


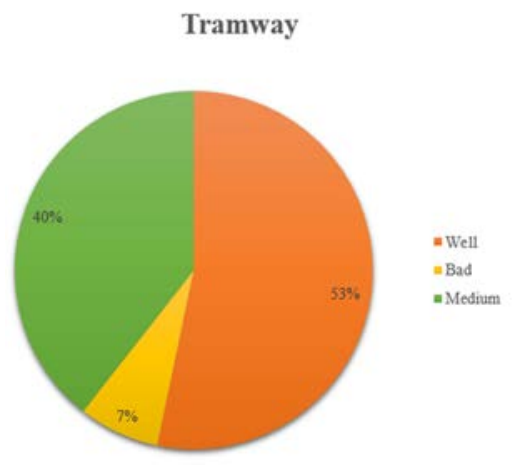

(a)

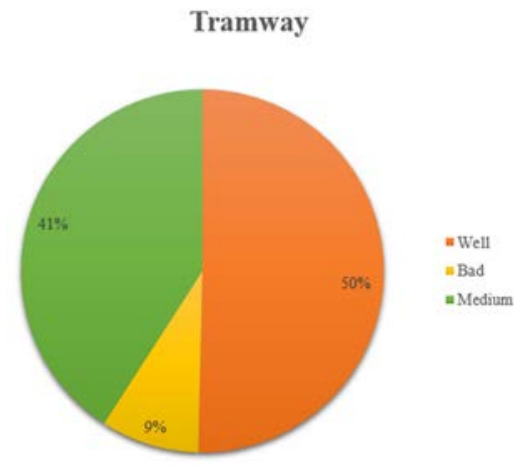

(b)

Figure 9: Operational problems mentioned by tram users. (a) TRAMWAY rotations; and (b) TRAMWAY prices.

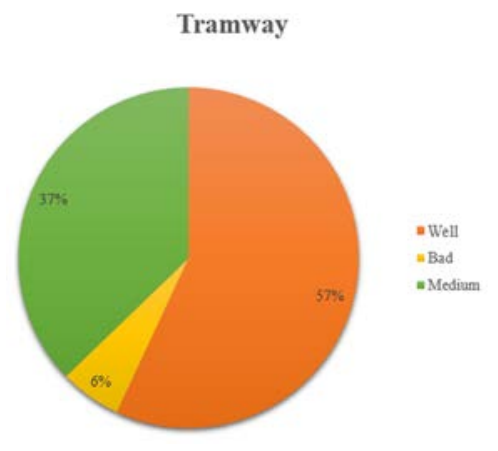

Figure 10: Notice on TRAMWAY stops.

Following this evaluation, we proposed improvements for this component: As mentioned for the buses, align the rotation of buses with that of the tram, as well as setting appropriate related drop-off points. Educate users by poster, information, direct contact, more. Also, ask the users to help preserve public goods and comfort in the buses and trams they use.

To better understand user requirements, we attempted to link the criteria of preference for different modes of transportation (Fig. 11). This graph highlights the main criteria of users in making the choice of their daily means of transport and commuting.

We note that bicycles are rarely used by the citizens of Constantine, due to the geographical nature of the city, which is characterised by having a mountainous nature, which would make it difficult to move about with this mode of transport, as well as the lack of a related culture of use.

Despite its acceptable fares, the bus remains the least preferred public means of transportation for users; on the other hand, the majority deems the Tramway as the most appreciated means of transport, because of its comfort, speed and safety. This mode of transport has to be practical for daily use. It must be said that both comfort and speed are the preferred criteria built into use of taxis and personal cars. We believe this must be taken into consideration when improving the system. 


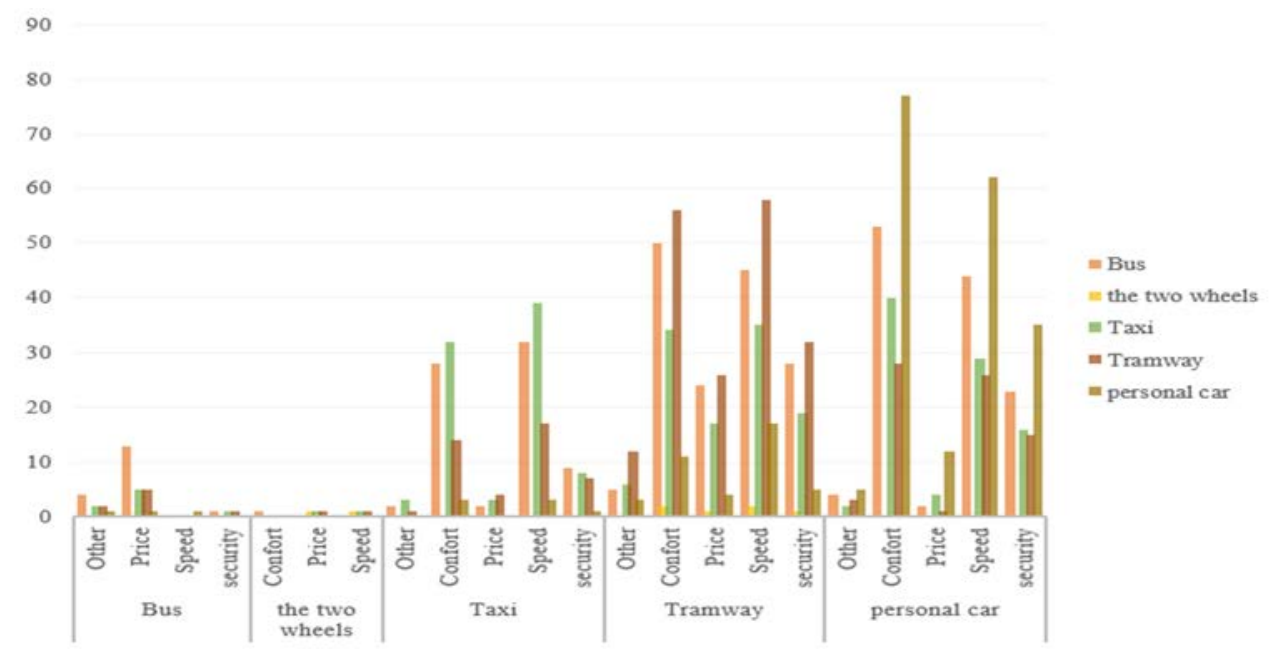

Figure 11: User-preferred criteria.

\subsection{Situational assessment}

For a clear view of the suggested improvements, we used a star diagram (spider diagram), a very representative tool for seeing the situation and improvements. Following the resolution of priority problems in the first iteration, Fig. 12 clearly shows the improved situation of the systems; however, it should be noted that this situation is not stable, as the system will always have to respond to new problems and a dynamic rotation of classification, so prioritisation and problem-solving must be applied, to even engage in a process of continuous improvement. No city on the planet can hope to solve the challenge posed by millions of daily trips, by only further developing its road transport system.

Before

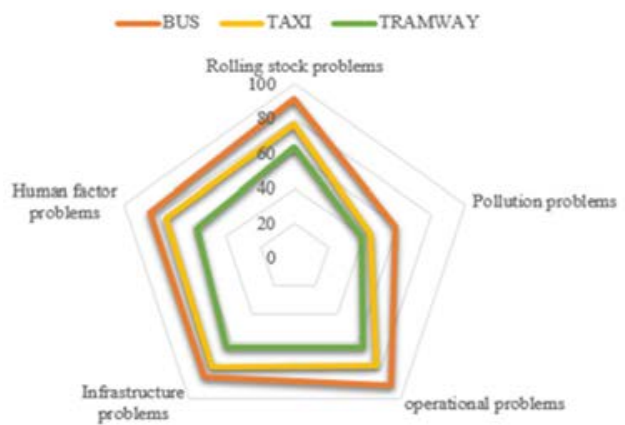

After

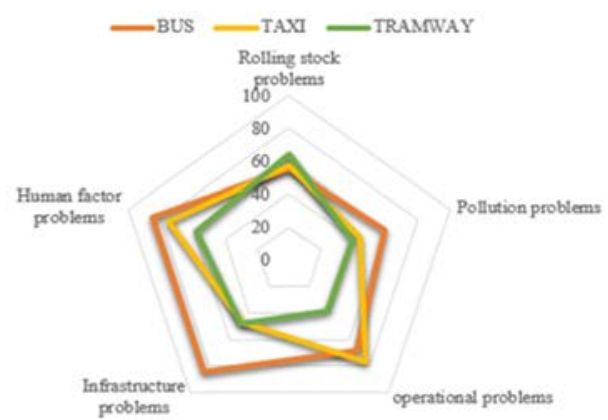

Figure 12: Situation assessment. Projected improvements in problem transport categories, before and after. 


\section{CONCLUSIONS}

In conclusion, we can confirm that a good urban transportation system is more than their bulk in helping along the good functioning of a city. Wasting time waiting for transportation or arriving late due to nearing its point of failure makes the local society generally less productive; and inevitably results in considerable economic loss, plus a negative contribution to the social and cultural health of the inhabitants. We encourage those concerned, especially our local authorities, to improve upon the road and transport network, and the management of travel, to achieve a more sustainable ecological economic and social sustainability, which currently remains insufficient. No city on the planet can hope to solve the challenge posed by millions of daily trips by developing only its road transportation system. We believe that the development of efficient means of transportation for the population generates positive economic externalities, which contribute significantly to a city's wealth creation and productivity. We hope our study helps show how the growing city of Constantine can be improved and the best approaches in several areas, to get there. 

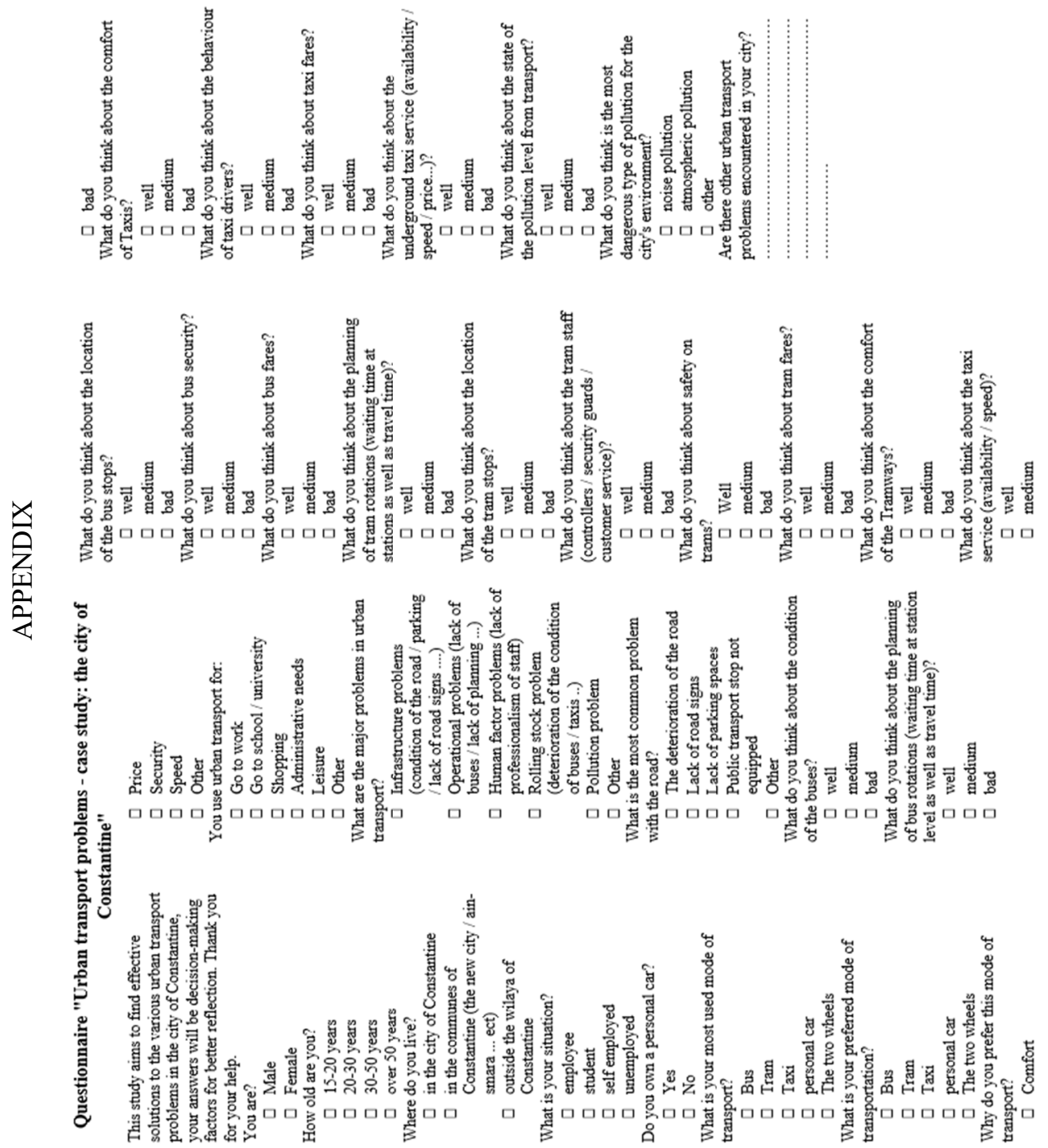


\section{REFERENCES}

[1] Saadi, A. \& Sahnoune, T., Le problème de la circulation et du stationnement dans le centre-ville de Constantine. Synthèse: Revue des Sciences et de la Technologie, 25(1), pp. 45-61, 2019.

[2] Benmechiche, M. \& Cherrad, S.E., La circulation routiere a Constantine et son effet sur son accessibilite. Sciences and Technologie. D, Sciences de la Terre, pp. 189-197, 2018.

[3] Mohanty, S.P., Choppali, U. \& Kougianos, E., Everything you wanted to know about smart cities: The internet of things is the backbone. IEEE Consumer Electronics Magazine, 5(3), pp. 60-70, 2016.

[4] Silva, B.N., Khan, M. \& Han, K., Towards sustainable smart cities: A review of trends, architecture, components, and open challenges in smart cities. Sustainable Cities and Society, 38, pp. 697-713, 2018.

[5] Rodríguez-Núñez, E. \& García-Palomares, J.C., Measuring the vulnerability of public transport networks. Journal of Transport Geography, 35, pp. 50-63, 2014.

[6] Day, R.J., Multiculturalism and the History of Canadian Diversity, University of Toronto Press, 2000.

[7] Yergin, D. \& Stanislaw, J., The Commanding Heights: The Battle for the World Economy, Simon and Schuster, 2002.

[8] Livingstone, D.N., Putting Science in its Place: Geographies of Scientific Knowledge, University of Chicago Press, 2010.

[9] Sallis, J.F., Bull, F., Burdett, R., Frank, L.D., Griffiths, P., Giles-Corti, B. \& Stevenson, M., Use of science to guide city planning policy and practice: How to achieve healthy and sustainable future cities. The Lancet, 388(10062), pp. 2936-2947, 2016.

[10] Nieuwenhuijsen, M.J., Khreis, H., Verlinghieri, E., Mueller, N. \& Rojas-Rueda, D., Participatory quantitative health impact assessment of urban and transport planning in cities: A review and research needs. Environment International, 103, pp. 61-72, 2017.

[11] Kamargianni, M., Li, W., Matyas, M. \& Schäfer, A., A critical review of new mobility services for urban transport. Transportation Research Procedia, 14, pp. 3294-3303, 2016.

[12] Chabane, L., Le secteur privé des transports urbains de voyageurs, quelles logiques de fonctionnement? Une enquête auprès des opérateurs privés à Alger. Les cahiers $d u$ créas, 109, pp. 89-120, 2014.

[13] Salhi, S. \& Bennour, Z., Evolution de la mobilité et de l'offre de transport public urbain dans les agglomérations d'Annaba et de Constantine. https://docplayer.fr/49282105Evolution-de-la-mobilite-et-de-l-offre-de-transport-public-urbain-dans-lesagglomerations-d-annaba-et-de-constantine.html. Accessed on 28 Dec. 2020.

[14] De Nazelle, A., Nieuwenhuijsen, M.J., Antó, J.M., Brauer, M., Briggs, D., BraunFahrlander, C. \& Hoek, G., Improving health through policies that promote active travel: A review of evidence to support integrated health impact assessment. Environment International, 37(4), pp. 766-777, 2011.

[15] Heath, G.W., Parra, D.C., Sarmiento, O.L., Andersen, L.B., Owen, N., Goenka, S. \& Lancet Physical Activity Series Working Group, Evidence-based intervention in physical activity: Lessons from around the world. The Lancet, 380(9838), pp. 272$281,2012$. 
[16] Mirabel, F. \& Reymond, M., Économie des Transports Urbains. La Découverte "Repères", 2013. https://www.cairn.info/economie-des-transports-urbains--9782707172938.htm. Accessed on 28 Dec. 2020.

[17] Centre de gestion de la fonction publique territoriale de la Sarthe, Document unique: Méthodologie d'évaluation des risques professionnels, 1 Dec. 2020.

[18] Cuppen, E., Breukers, S., Hisschemöller, M. \& Bergsma, E., Q methodology to select participants for a stakeholder dialogue on energy options from biomass in the Netherlands. Ecological Economics, 69(3), pp. 579-591, 2010.

[19] Dobele, A.R., Westberg, K., Steel, M. \& Flowers, K., An examination of corporate social responsibility implementation and stakeholder engagement: A case study in the Australian mining industry. Business Strategy and the Environment, 23(3), pp. 145159, 2014.

[20] Lyes, C., Algérie: Voici les Chiffres des Réseaux Sociaux en 2020. https://www.dzairdaily.com/algerie-chiffres-reseaux-sociaux-2020/. Accessed on: 28 Dec. 2020.

[21] Kouaci, H. \& Telahigue, I., Les réseaux sociaux en Algérie: Adoption massive par les internautes et grande opportunité pour les entreprises. Revue des Reformes Economiques et Intégration dans L'économie Mondiale, 11(22), pp. 87-114.

[22] Zapier, I., The Ultimate guide to Google Sheets. https://zapier.com/learn/googlesheets/. Accessed on: 28 Dec. 2020.

[23] Bélorgey, P., La boîte à outils de la gestion du temps: 71 outils and méthodes. 2nd ed., Dunod, 2019. 